\title{
Forced Expiratory Flow in 0.1 Second
}

National Cancer Institute

\section{Source}

National Cancer Institute. Forced Expiratory Flow in 0.1 Second. NCI Thesaurus. Code C139251.

The forced expiratory flow rate during the first 0.1 seconds of a forced exhalation. 